\title{
Study on Bagasse Reinforced Waste Thermoplastic Composite: Compressive Strength and Water Absorption
}

\author{
Tekalign Aregu Tikish*, Nefisa Abdulkadir Ali \\ Materials Science Directorate, Emerging Technology Center, Ethiopian Biotechnology Institute, Addis Ababa, Ethiopia \\ Email address: \\ tekisht@gmail.com (T. A. Tikish), nefoabdul@gmail.com (N. A. Ali) \\ ${ }^{*}$ Corresponding author \\ To cite this article: \\ Tekalign Aregu Tikish, Nefisa Abdulkadir Ali. Study on Bagasse Reinforced Waste Thermoplastic Composite: Compressive Strength and \\ Water Absorption. American Journal of Mechanical and Materials Engineering. Vol. 5, No. 1, 2021, pp. 5-10. \\ doi: 10.11648/j.ajmme.20210501.12
}

Received: December 31, 2021; Accepted: January 15, 2021; Published: March 10, 2021

\begin{abstract}
This study reported that the compressive strength and water absorption properties of thermoplastic reinforced with bagasse and sand composite materials. In recent times, the population of the country is increasing rapidly, and in parallel, their demand for residence also increasing. However, there is a shortage of resources of former conventional construction materials to satisfy their needs. Besides this, the former conventional is environmentally degradable. Moreover, construction cost increases from time to time. Due to this reason, the choice of an alternative material is needed in construction. Bio-based composite has developed from sugarcane bagasse, sand as reinforcement, and the recycled thermoplastic as the matrix. The biocomposite specimen was prepared for compressive strength and water absorption test. The compressive strength and water absorption test of the biocomposite are tested. The compressive strength test was conducted by Toni Technik automatic compressive strength test machine. The result shows that the average compressive strength of $3.01 \mathrm{MPa}$. With the dispersion 0.73 from the mean average strength. The dimensional change due to water absorption is $1.24 \%$ within 24 hours. This result shows a small dimensional change. The result compared with Ethiopian Standard building Code (ESC D3 301) and the developed bio-composite using sand, sugar cane bagasse and thermoplastics composite was a satisfactory result of residential construction.
\end{abstract}

Keywords: Biocomposite, Bagasse, Thermoplastic, Compressive Strength, Water Absorption, Diffusion Coefficient

\section{Introduction}

The thought of using different materials for the building has a long-time history and complex. In the early time, the human-made their shelters or house from naturally-occurring materials. Since then, the construction materials have improved from time to time. The idea of using two or more materials for the building has a long history. For instance, the first uses of composites date back to the 1500s B.C., when early Egyptians and Mesopotamian settlers used a mixture of mud and straw to create strong and durable buildings. Straw continued to reinforce ancient composite products including pottery and boats $[1,2]$.

According to Woiundimagegnehu (2009) in his study on affordable housing for lower and middle-income groups in Ethiopia indicated that the cost of construction materials takes $70 \%$ of the total construction cost [3].
Nowadays, engineers and researchers were developed, new construction materials for different advantages like Lightweight, high specific stiffness and strength, Easy moldable to complex forms, Easy bendable, Good dumping, Low electrical conductivity, and thermal expansion, good fatigue resistance, and lower the overall system costs [4].

Bio-based composite is one of the hot areas in the fabrication of construction materials for residential and commercial buildings. Bio-composites have been the subject of extensive research, specifically in the construction and building industry due to their many advantages such as lower weight, and lower manufacturing costs. These days, not only builders, but also many homeowners are interested in using bio-composites for different products such as decking, fencing, and so on $[5,6]$.

Agri-fiber boards are made from the fibrous residue of the agricultural process. Wheat, rice, rye-grass, soybean straw, 
corn stalks, hemp, rice hulls, flax Shives, sunflower stalks, and seed hulls are just some of the agricultural fibers finding their way into the building and furniture materials. Recycledcontent drywall contains "synthetic" gypsum, a waste byproduct of flue gas scrubbers, and reduces the demand for virgin gypsum mined from the ocean floor $[7,8]$.

In the present study, the thermoplastic polymer is used as a matrix polymer and bio-fibers (bagasse) as reinforcing filler to develop a bio-composite wall and/ or partition. Test and evaluate the bio-composites property to have the possibility of residential construction.

\section{Methods}

\subsection{Materials}

All Thermoplastic plastic waste was collected from Ethiopian Biotechnology Institute and Bagasse was collected from Wonji/Shewa sugar factory and Sand from Mojo river.

\subsection{Sample Preparation}

Two types of bio-composites have been produced in a different composition of bagasse in table 1 below.

Table 1. Specimen Weight composition.

\begin{tabular}{lll}
\hline Composite Type & Components Materials & Wt. of percentage (g) \\
\hline & & $70: 20: 10$ \\
Type 1 & Thermoplastics & 1400 \\
& Bagasse & 400 \\
& Sand & 200 \\
& & $80: 10: 10$ \\
Type 2 & Thermoplastics & 1600 \\
& Bagasse & 200 \\
& Sand & 200 \\
\hline
\end{tabular}

The samples were prepared using the following steps:

1. Preparing the bagasse, it was included girding and drying in a $25^{\circ} \mathrm{C}$ oven

2. Preparing the thermoplastics recycled. It was recycled thermoplastics need washing,

Cutting and drying

3. Preparing the sand, pumice, and red ash

3. Weigh each material in different ratio composition

4. Mixing the prepared bagasse and sand, pumice, and red ash

5. Heating the thermoplastic materials less than $175^{\circ} \mathrm{C}$

6. Mix step 4 with melted thermoplastics in step 5 .

7. Transfer the blends into the mold for getting the desired shape, finishing, and cooling by air.

\subsection{Tests}

\subsubsection{Compression Strength Test}

The compressive strength test is one of the quality controls measures that specify the amount or capacity of maximum load the material can bear before it reaches the fracturing stage. The test piece which is mostly prepared in cubic, prism, or cylindrical shape is compressed between two platens of a compression-testing machine by a gradually applied load.
The test is conducted using Instron Universal Testing Machine [14].

$$
\operatorname{Stress}(\delta)=\frac{F}{A}
$$

The test done is all about safety. The material should resist the upcoming loads before any damage happens in humans and even on the structure in real construction application.

Second, it is required to meet the defined minimum compressive strength rules and regulations of a country or universal standard depending on construction type.

Last but not least, it is useful to judge the compatibility of the material to other materials.

\subsubsection{Water Absorption Test}

The water absorption test is used to determine the rate of absorption of water by a composite material by measuring the increase in the size and weight of a specimen resulting from the absorption of water as a function of time when the specimen is submerged to water. The absorption of water by such specimens is directly related to permeability. Higher permeability led to the presence of a chemical reaction that can destroy the material easily, whereas low permeability of materials can help the resistance to penetration of water, chloride ions, sulfate ions, alkali ions, and other harmful substances which can cause a chemical attack and lower the durability of the material [9].

Water absorption can be expressed as an increase in weight percent by ASTM C1585- 13 standard test method.

$$
\mathrm{W} \%=\frac{\mathrm{W}_{\text {wet }}-\mathrm{W}_{\text {dry }}}{\mathrm{W}_{\mathrm{dry}}} * 100
$$

Were, $W_{\text {wet }}$ is Wet weight and $W_{d r y}$ is Dry weight)/ Dry weight

The water uptake and water absorption rate generally increase when there is an increase in the fiber volume fraction. According to the typical Fickian's moisture absorption model [10], most of the water absorption behavior of composite samples behaves linearly at the beginning of the test and reach saturation later in the test. The average diffusion coefficient $(D)$ of the composites was calculated from the measurements of weight gain and the initial slope of the weight gain curves versus the square root of time, as follows:

$$
\text { Diffusion Coefficient }(D)=\pi\left(\frac{\mathrm{kh}}{4 \mathrm{M}_{\infty}}\right)^{2}
$$

Where $h$ is the thickness of the specimens, $M \infty$ is the maximum weight gain, and $k$ is the slope of the initial plot $M(t)$ very $\sqrt{t}$.

The Dimensional Change is measured using Verner caliper measure before and after the specimen immersed for 24 hours. It is expressed as:

$$
\mathrm{D} \%=\frac{\mathrm{D}_{\mathrm{After}}-\mathrm{D}_{\text {Before }}}{\mathrm{D}_{\text {Before }}}
$$

The durability of a material, mainly composite material, has a great impact on the product's service life. The capacity 
of a fluid to penetrate the composite material does matter on the durability of the composite construction materials in different aspects like a chemical reaction formation.

\section{Analysis of Test Result}

\subsection{Analysis of the Compressive Strength}

The purpose of this work was to conduct a statistical analysis of the compressive strength of biocomposite construction materials. Specimens were cast in two different sizes of as shown in figure 1 . The specimens were tested in

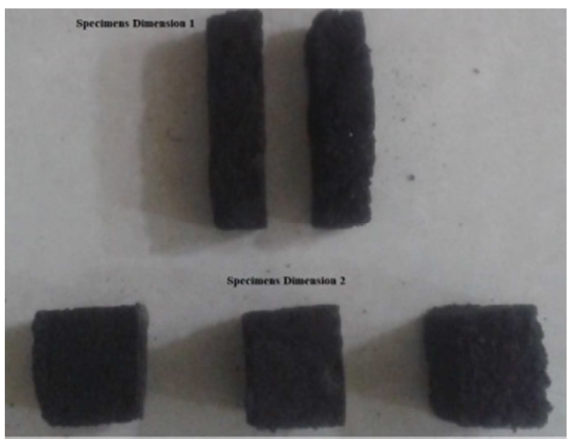

Figure 1. The specimens to compressive test. Ethiopian Conformity assessment Enterprise Laboratories.

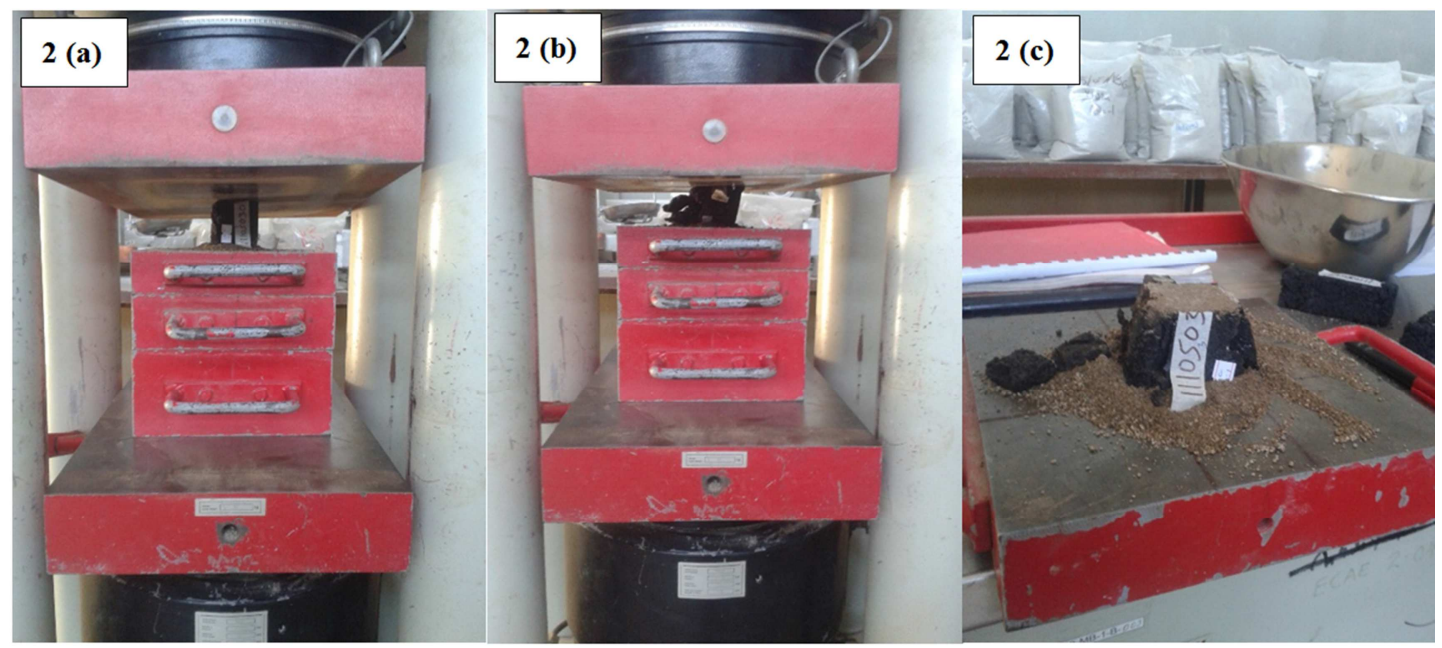

Figure 2. Compressive strength Test (a) before, (b) during and (c) After Failure.

The compressive strength test was conducted by Toni Technik automatic compressive strength test machine on building materials as shown in figure 2 . The specimen was compressed between two platens of a compression-testing machine by a gradually applied load. The sand was used to cape the sample. The results of the compressive strength shown in tables 2 and 3 below:

Table 2. The Compressive Strength of type 1 Specimen.

\begin{tabular}{lllllll}
\hline \multirow{2}{*}{ Lab. Des. No } & \multirow{2}{*}{ Ser. No } & \multirow{2}{*}{ Length $[\mathbf{m m}]$} & \multirow{2}{*}{ Breadth $[\mathbf{m m}]$} & \multirow{2}{*}{ Force $[\mathbf{K N}]$} & & \multicolumn{2}{c}{ Compressive Strength } \\
\cline { 6 - 8 } & & & & $\mathbf{N} / \mathbf{m m}^{2}$ & $\mathbf{K g} / \mathbf{c m}^{2}$ \\
& 1 & 30.61 & 30.59 & 4 & 4.27 & 42.7 \\
\end{tabular}

Table 3. The Compressive Strength of type 2 Specimen.

\begin{tabular}{lllllll}
\hline \multirow{2}{*}{ Lab. Des. No } & \multirow{2}{*}{ Ser. No } & Length $[\mathbf{m m}]$ & \multirow{2}{*}{ Breadth $[\mathbf{m m}]$} & \multirow{2}{*}{ Force $[\mathbf{K N}]$} & \multicolumn{2}{l}{ Compressive Strength } \\
\cline { 5 - 7 } & & & & $\mathbf{N} / \mathbf{m m}^{2}$ & $\mathbf{K g} / \mathbf{c m}^{2}$ \\
\hline 11105030 & 1 & 56.20 & 51.27 & 7 & 2.43 & 24.3 \\
& 2 & 52.99 & 50.18 & 7 & 2.63 & 26.3 \\
\hline
\end{tabular}

The results of this investigation show that the average compressive strength of $3.01 \mathrm{MPa}$. With the dispersion 0.73 from the mean average strength.

According to the Ethiopian standard Code (ESC D3 301), the minimum compressive strength is indicated in the following table 3 below. The Ethiopian building standard Code classified the Hollow concrete blocks into three classes. Such as, class A and B include load beading units and suitable for: External walls pointed, rendered, and plastered, the inner leaf of cavity walls or stone masonry, internal walls or partitions, panels in steel-framed and reinforced steel- framed buildings [11].

Table 3. The Ethiopian standard Code (ESC D3 301).

\begin{tabular}{lllll}
\hline \multirow{2}{*}{ Class } & \multicolumn{2}{l}{ Average of six Units } & \multicolumn{2}{c}{ Individual Units } \\
\cline { 2 - 5 } & $\mathbf{M p a}$ & $\mathbf{K g} / \mathbf{c m}^{\mathbf{2}}$ & $\mathbf{M p a}$ & $\mathbf{K g} / \mathbf{c m}^{\mathbf{2}}$ \\
\hline A & 4.2 & 4.2 & 3.8 & 3.8 \\
B & 3.5 & 3.5 & 3.2 & 3.2 \\
C & 2.0 & 2.0 & 1.8 & 1.8 \\
\hline
\end{tabular}

Whereas class $\mathrm{C}$ is categorized as non-load-bearing units suitable for Non-load bearing walls and partitions, none load 
beating internal panels in steel-framed and reinforced concrete buildings.

The result of this study is compared with the Ethiopian standard Code classification in the following figure 3.

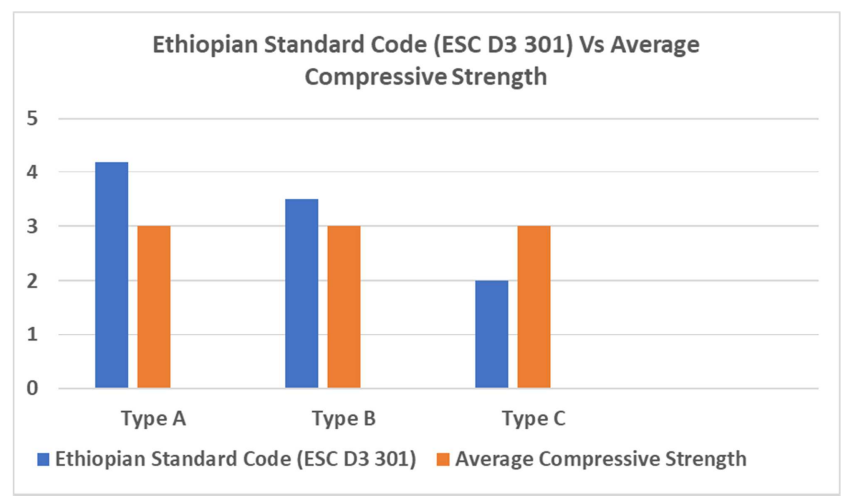

Figure 3. The compressive strength of the Ethiopian standard code (ESC D3 301) compared to specimens composite materials.

The result of the study indicated that the biocomposite materials are satisfied with the Ethiopian building standard code ESC D3 301 class C. And suitable for non-load bearing walls and portions. Even if some individual results 4.27 Mpa satisfy class A and B load-bearing standards. In the study Miyahara et al. on the composite from plastic waste and Sugar cane bagasse fiber reported that the compression strength $11.9,13.9$, and $8.9 \mathrm{MPa}$ with moisture retention 1.8 , 1.9 , and $2.4 \%$ respectively. The research pointed out that moisture retention increased with the amount of sugarcane fiber in the composite [12].

\subsection{Analysis of Water Absorption Test}

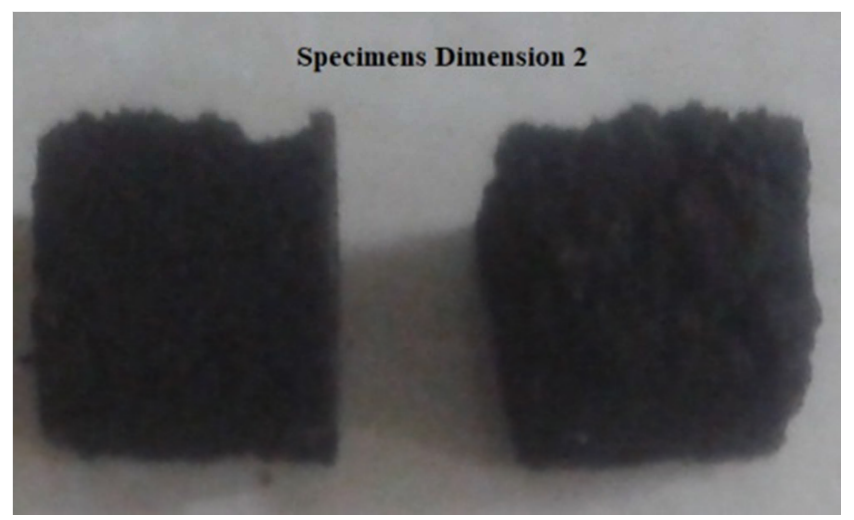

Figure 4. Specimens for water absorption.

Most biocomposites absorb moisture in humid environments or when immersed in water, however, the rate of degradation and water uptake behavior is different for each material. Moisture absorption in bio-reinforced composites can cause a huge variation in physical, mechanical, and thermal properties [13]. The water absorption behavior of biocomposite construction materials. The water absorption analysis is based on the weight percentage, calculation of diffusion coefficient, and physical dimensional changes. The specimens in figure 4 were tested for water absorption.
The result of this investigation provides the weight percentage of biocomposite materials water absorption. The result indicates that $6.5 \%$. According to the construction materials code, water absorption of less than $7 \%$ satisfies the standards. Compared to other research work the data that has been analyzed, samples tested showed approximately the water absorption values are $21 \%$ to $35 \%$. The combination of short fibre and granules that called both fibers has less absorption compared with a fibreboard that makes from short fibre only [14]. In the studies conducted by Mishra et al., 288 the water absorption of pineapple leaf fiber and sisal fiberpolyester biocomposites were found to reduce approximately $5-7 \%$ at 24 hours after hybridization with glass fiber [15]. In the study by Tewari et al., The water absorption capacity was found to be maximum for $30 \mathrm{wt} \%$ bagasse-5 $\mathrm{wt} \%$ glass fiber reinforced composite, where there was a percentage increase of $7.83 \%$ in the weight of the material with compressive strength 1.83 MPa [16].

The other examination was determining the water diffusion coefficients of the biocomposite materials. The average diffusion coefficient (D) of the composites was calculated from the measurements of weight gain and the initial slope of the weight gain curves versus the square root of time, as shown in figure 5 , the result has shown that $5.151 * 10^{-6} \mathrm{~mm} / \mathrm{s}$. The diffusion coefficient describes the water transport phenomena through biocomposite materials. At the initial time rate of water, diffusion is high and linear as time increases the slowdown and finally reaches a saturation level. This phenomenon indicated that bio-composite materials have hydrophilic properties. Because the bagasse contains cellulose and the rough surface of the biocomposite materials.

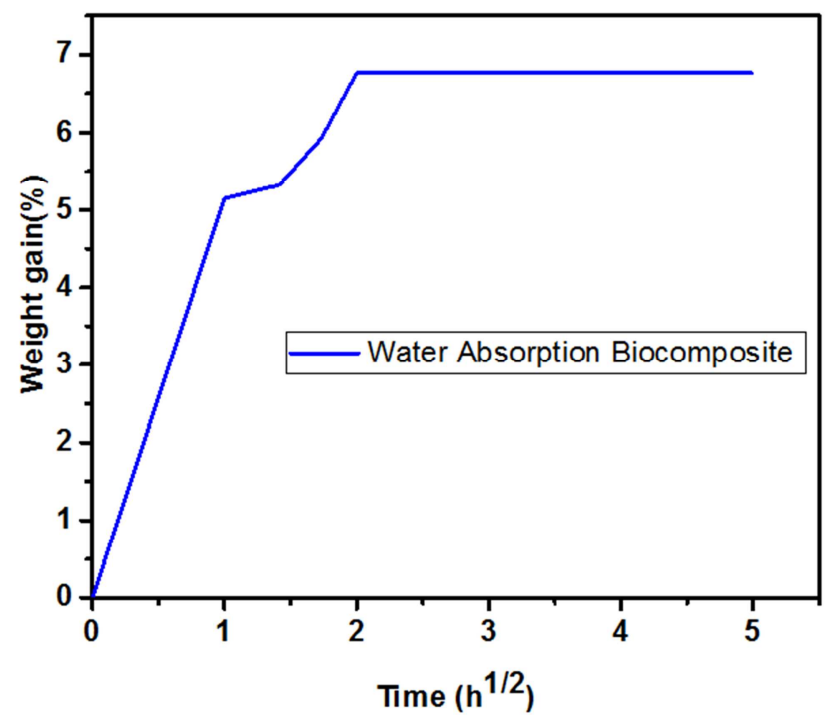

Figure 5. Water Absorption of Biocomposite Specimens.

The dimensional change due to water absorption is $1.24 \%$ within 24 hours. This result shows a small dimensional change. Figure 6 below shows the relationship between water absorption with dimensional changes. In the study on bagasse/HDPE, Mulinari et al have been reported that water absorption decreases the mechanical properties of composite 
materials and once the water diffused inside it changes the structure and properties of the composite materials duet to the water molecule makes a hydrogen bond with cellulose fiber. They pointed out that the composite modified with zirconium Oxychloride showed improved mechanical properties [17].

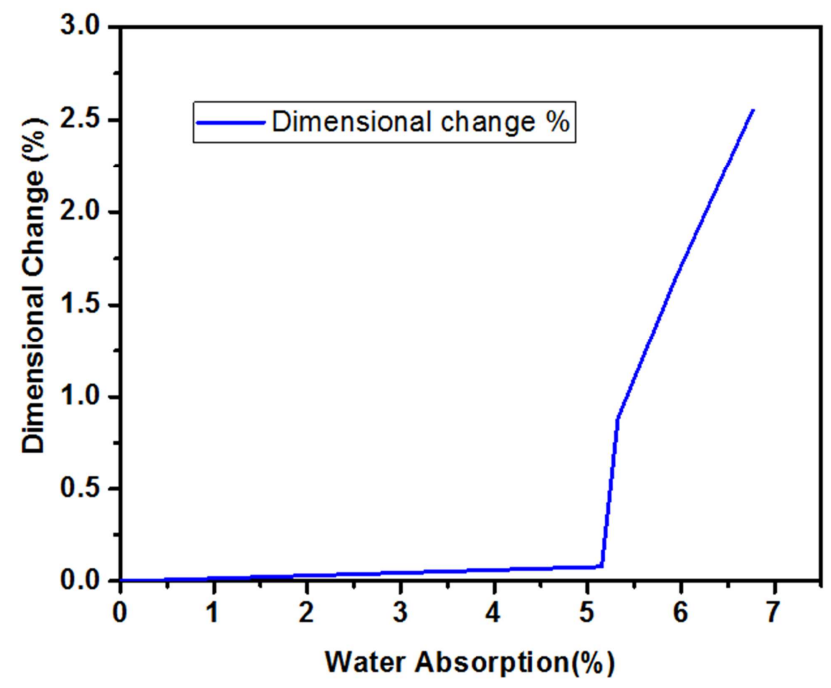

Figure 6. The relation between the dimensional change and water absorption.

\section{Conclusion}

The result of this work showed that the following conclusion. The produced bio-based composite materials could be suitable for partition and walls. The developed biocomposite using sand, sugar cane bagasse and thermoplastics composite was a very satisfactory result and also satisfy the Ethiopian standard Code (ESC D3 301).

The recycled thermoplastics (drinking bottle) reinforced with sugar cane bagasse and sand have shown that an alternative construction material. Reduced the landfill of thermoplastic drinking bottles after uses. And sugar cane bagasse also the byproduct of sugar factory which opens an opportunity for environmental protection as well as a resource in producing alternative bio-based composite construction materials.

Comparing with conventional constructive materials to the Hollow concrete blocks, the bio-based composite material has shown lightweight, easily produced without high technology, and cost-effective. This bio-based composite material has good opportunities for the future in substituting conventional construction materials.

The manufacturing and distribution of this bio-based composite open economic opportunities for the group society. It needs modification of effective methods and small-scale business.

\section{Acknowledgements}

I would like to thank Wonji/Shewa Sugar Factory for providing sugarcane bagasse and good collaboration. Also, I extend my gratitude to Ethiopian Conformity Assessment Enterprise Materials Test and the technicians.

\section{References}

[1] Nagavally, R. R. (2017). Composite materials-history, type, fabrication, techniques, advantages, and applications. International Journal of Mechanical And Production Engineering, 5: 2320-2092.

[2] Ngo, T.-D. (2019). Introduction to composite materials. IntechOpen, 1-27.

[3] Woundimagegnehu, T. (2009). Affordable houses for middle and low-income groups. Addis Ababa: Urban Development Policy, Ethiopia: Artistic press.

[4] Layth Mohammed, M. N. (2015). Review on natural fiber reinforced polymer composite and Its applications. International Journal of Polymer Science, 1-15.

[5] Chang, B. P., Mohanty, A. K., \& Misra, M. (2020). Studies on the durability of sustainable biobased composites: a review. Royal Society of Chemistry, 17955-17999.

[6] Tegegne, A., \& Aregu, T. (2014). Experimental development of bio-based polymer matrix building material and a fishbone diagram for material effect on quality. International Journal for Quality Research, 8: 277-292.

[7] Yasina, M., Bhuttob, A. W., Bazmia, A. A., \& Karimb, S. (2010). Efficient utilization of rice-wheat straw to produce value-added composite products. International Journal of Chemical and Environmental Engineering, 136-143.

[8] Hammajam, A., \& Sapuan, S. M. (2013). Review of agrowaste plastic composites production. Journal of Minerals and Materials Characterization and Engineering, 1: 271-279.

[9] Zhang, S. P., \& Zong, L. (2014). Evaluation of the relationship between water absorption and Durability of concrete materials. Advances in Materials Science and Engineering, 1-8.

[10] Muñoz, E., \& García-Manrique, J. A. (2015). Water absorption behavior and Its Effect on the mechanical properties of flax fiber-reinforced bio epoxy composites. International Journal of Polymer Science, 1-10.

[11] Alemeshet, A. M. (2019). Investigating the acceptable quantity of fine aggregate to be replaced with sawdust to obtain the strong, lightweight, and economical result for HCB production. International Journal of Advanced Research, Ideas, and Innovations in Technology, 5: 391-395.

[12] Miyahara, R. Y., Melquiades, F. L., Ligowski, E., Santos, A., F. S., \& Antunes Junior, O. R. ( 2018). Preparation and characterization of composites from plastic waste and sugar cane fiber. Polímeros, 28: 147-154.

[13] Al-Maharma, A. Y., \& Al-Huniti, N. (2019). A critical review of the parameters affecting the effectiveness of moisture absorption treatments used for natural composites. Journal of Composite Science, 27: 1-38.

[14] Al Bakri, A. M. M., Liyana, J., Norazian, M. N., Kamarudin, H., \& Ruzaidi, C. M. (2013). Mechanical Properties of Polymer Composites with Sugarcane Bagasse Filler. Advanced Materials Research, 740, 739-744. 
[15] Mishra, S., Mohanty, A. K., Drzal, L. T., Misra, M., Parija, S., Nayak, S. K. and Tripathy, S. S. (2003) Studies on Mechanical Performance of Biofiber/Glass Reinforced Polyester Hybrid Composites. Composites Science and Technology, 63: 13771385 .

[16] Tewari, M., Singh, V. K., Gope, P. C., \& Chaudhary, A. K. (2012). Evaluation of mechanical properties of bagasse-glass fiber reinforced. J. Mater. Environ. Sci, 3: 171-184.
[17] Mulinari, D. R., Voorwal, H. J., Cioff, M. O., Rocha, G. J., \& Diliva, M. L. (2010). Surface modification of sugarcane bagasse cellulose and its effect on mechanical and water absorption properties of sugarcane bagasse cellulose composite. BioResources.com, 5: 661-671. 